\title{
9. DIAGENESIS OF SANDSTONE FROM STRATIGRAPHIC UNITS III AND IV, SITE 537¹
}

\author{
Earle F. McBride, Department of Geological Sciences, University of Texas at Austin, Austin, Texas
}

\begin{abstract}
Three sandstone samples each from Stratigraphic Units III and IV were studied to determine their diagenetic history. The sandstone bodies probably had a common provenance and were essentially granitic debris when deposited. Because grains were deposited in different environments, they followed totally different diagenetic pathways.

Sands in Unit III, which possibly were deposited as fan deltas in a marine setting, are interbedded with carbonate mud. The inferred sequence of diagenetic events that the sediment underwent includes the formation of thin $\mathrm{K}$-feldspar overgrowths on detrital K-feldspar grains; replacement of much feldspar (chiefly plagioclase) by micrite; dolomitization of much micrite; development of secondary porosity $(\sim 10 \%)$ by dissolution of feldspar and micrite; generation of pyrite, possibly by reaction of migrating $\mathrm{H}_{2} \mathrm{~S}$ with hematite that was present as grain coatings (now gone) on detrital grains.

Sands of Unit IV, which were deposited as alluvial deposits, first underwent diagenesis under the influence of meteoric water, later by formation water of uncertain origin. The inferred diagenetic sequence includes the development of clay skins on detrital sand grains during the infiltration of meteoric water; hydrolysis and oxidation of unstable detrital grains (chiefly plagioclase and ferromagnesian minerals) to produce kaolinite, mixed-layer clays, and hematite that precipitated in the pores of the sand; trivial development of secondary pores by late-stage dissolution of $\mathrm{K}$-feldspar along cleavage planes; and migration of $\mathrm{H}_{2} \mathrm{~S}$ through the sandstone to locally reduce the hematite and bleach the rocks.
\end{abstract}

\section{INTRODUCTION}

This paper concerns the petrography and diagenesis of sandstone and sandstone lenses in carbonate rocks from two core segments of Hole 537 of Leg 77 of the Deep Sea Drilling Project. To determine the diagenetic history of the sandstones, the following samples were studied: three samples from Stratigraphic Unit III (Samples 537-11-1, 99-101 cm; 537-11-1, 33-35 cm; and $537-11-1,118-120 \mathrm{~cm}$ ) and three samples from Stratigraphic Unit IV (Samples 537-13-2, 5-7 cm; 537-13-1, $112-114 \mathrm{~cm}$; and 537-13-1, 17-19 cm). Thin sections were made from samples that had been impregnated with blue-dyed epoxy resin and were studied in both transmitted and reflected light using a petrographic microscope.

The sandstone samples in both core segments are arkoses that probably had similar source rocks (chiefly granitic), but the sands were deposited in different environments and had distinctly different diagenetic histories. Sandstone of Core 537-11 was deposited as lenses less than $1 \mathrm{~cm}$ thick in marine carbonate mud. The rocks are well bedded, greenish-gray, pyritiferous, and strongly dolomitized (40-60\%). Sandstones of Core 537-13 are red beds of possible fluvial origin that lack carbonate minerals, but have pervasive authigenic clay matrix stained by hematite that is typical of red beds formed by postdepositional alteration of arkosic (granite wash) debris.

\section{SAMPLES FROM UNIT III (CORE 537-11)}

Detrital grains make up laminae of sandstone from 1 to $5 \mathrm{~mm}$ thick and also occur as evenly scattered grains in dolomite. Long axes of elongate grains show a strong

\footnotetext{
${ }^{1}$ Buffler, R. T., Schlager, W., et al., Init. Repts. DSDP,77: Washington (U.S. Govt. Printing Office).
}

preferred orientation that defines bedding. Grains are poorly sorted and range from silt-size to $2 \mathrm{~mm}$ in diameter. Detrital grains are surrounded by a mixture of micrite (10-30\% of the rock) and euhedral rhombs of dolomite $(30-60 \%)$ that reach $0.05 \mathrm{~mm}$ (Figs. 1-3). There are many micrite patches the same size as detrital terrigenous grains (Fig. 3), so it is not clear whether the grains are micrite allochems or micritized terrigenous grains. Dolomite was formed by replacement of micrite.

Terrigenous grains are similar in composition to those of Core 537-13, which were studied in more detail and are described later. Unlike samples from Core 537-13, samples from Core 537-11 have trace amounts of micas and hornblende. Transported and abraded calcite skeletal grains (mostly or entirely mollusks) are also present in trace amounts.

Primary porosity was essentially destroyed by the combination of compaction and cementation by micrite and to a minor degree by the development of thin K-feldspar overgrowths on K-feldspar grains (Fig. 2). Secondary porosity, estimated to be from 5 to $10 \%$, developed during dolomitization, by the dissolution of K-feldspar and plagioclase to form "skeletal" grains or molds, and by dissolution of minor amounts of micrite (Fig. 3).

Cubes as well as framboids of pyrite are conspicuous throughout the samples.

\section{SAMPLES FROM UNIT IV (CORE 537-13)}

These are red to purple sandstone characterized by abundant (up to 50\%) authigenic clay "matrix" (Figs. 4-8). Typical of red beds that have formed by extensive diagenetic alteration of first-cycle granitic detritus, the original texture and composition of the samples have been strongly modified. The detrital fraction is chiefly coarse and very coarse sand grains, but granules and silt-sized particles are present also. No bedding or pre- 


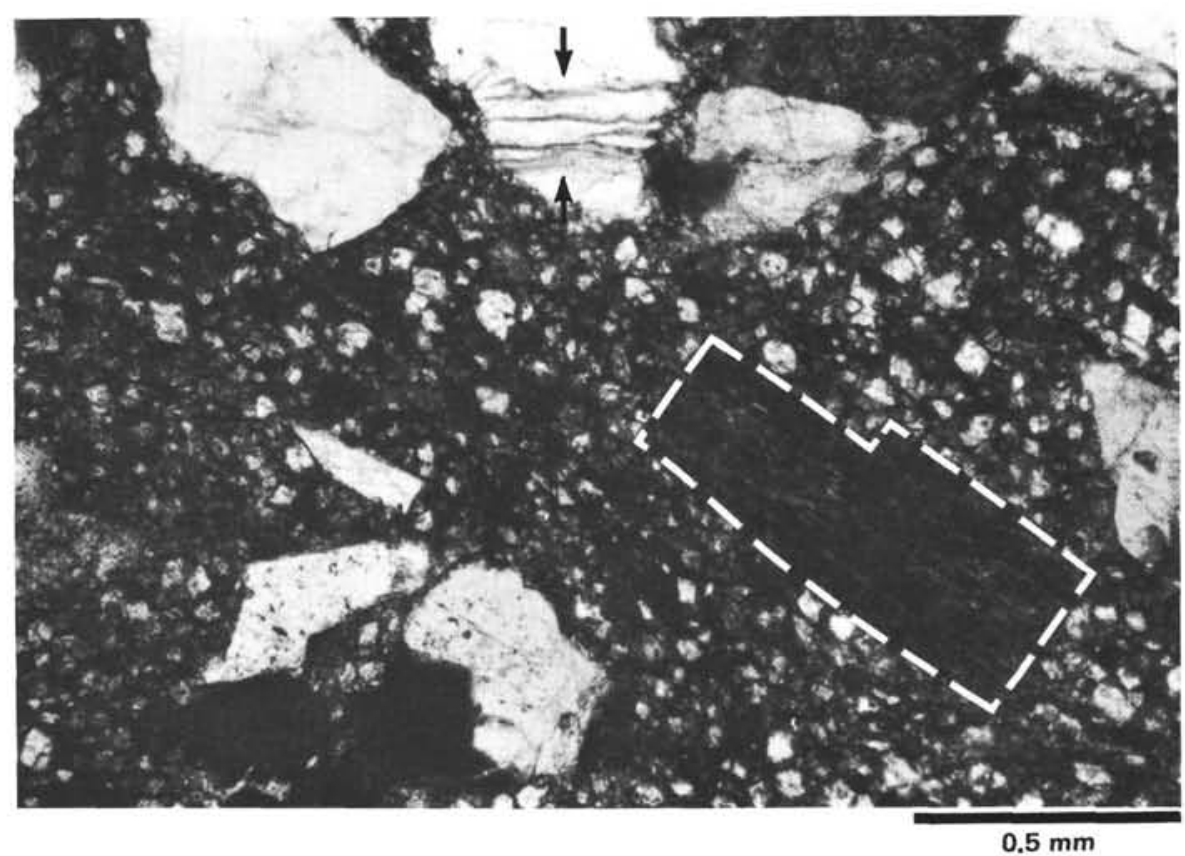

Figure 1. Scattered detrital grains in dolomitized micrite host. Vacuolized, cloudy K-feldspar grain is outlined by a dashed border. Open pores in a quartz grain (arrows) formed where calcite that replaced quartz along hairline fractures was dissolved after burial. Sample 537-11-1, $33 \mathrm{~cm}$.

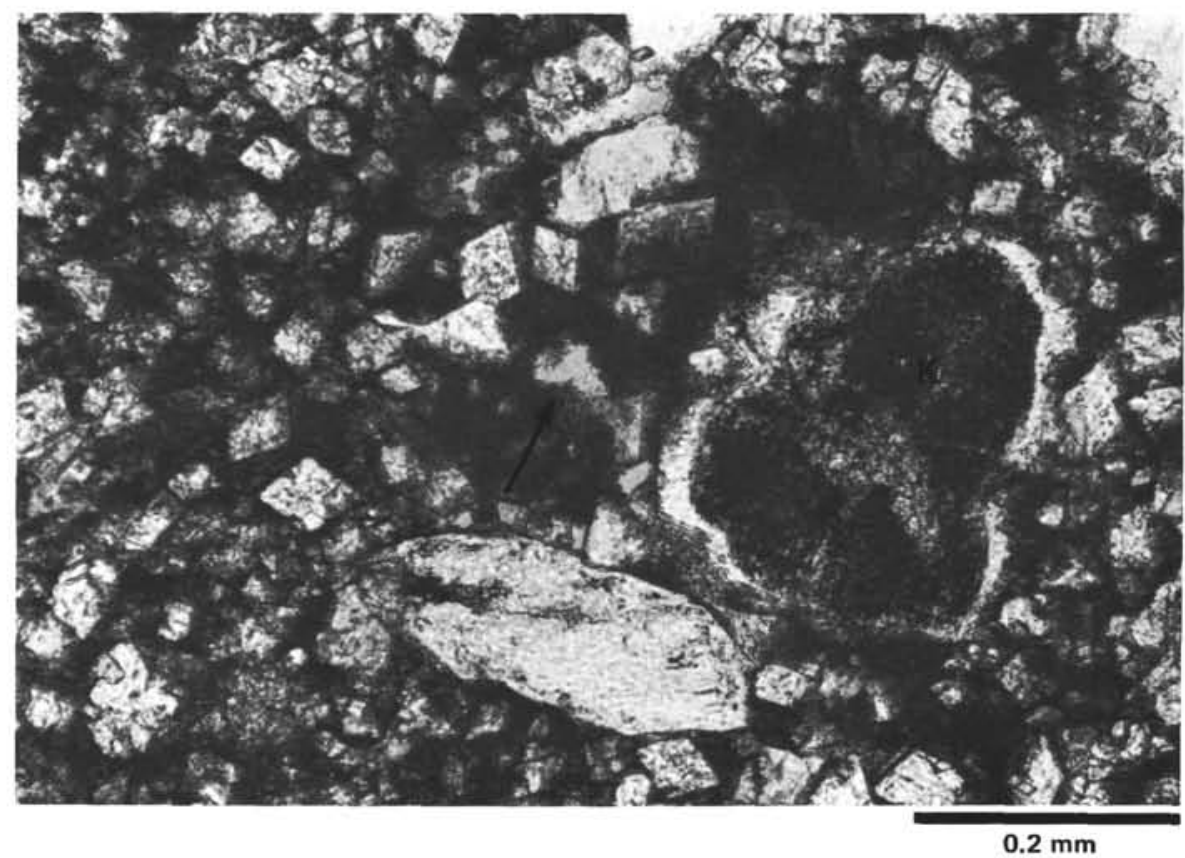

Figure 2. The texture of this sand lens in limestone has been severely modified by the growth of authigenic dolomite rhombs. A vacuolized, cloudy K-feldspar grain $(\mathrm{K})$ has a clear overgrowth of orthoclase. Arrow indicates a late-stage dissolution pore. Sample 537-11-1, $19 \mathrm{~cm}$.

ferred alignment of long axes of grains is present in the samples studied.

Framework grains are about $50 \% \mathrm{~K}$-feldspar, $45 \%$ quartz, and $5 \%$ plagioclase and rock fragments (chiefly quartz-feldspar intergrowths and metasiltstone). No micas or accessory minerals are present. Quartz is very angular, strained, and has many embayments that are typi- cal of those formed in soil horizons (Figs. 4 and 5). Polycrystalline quartz grains are common.

$\mathrm{K}$-feldspar is moderately to strongly vacuolized (Fig. 8 ) and some grains have late-stage dissolution canals along cleavages or even more extensive dissolution pores (Fig. 9). A few grains have been dismembered into six or more pieces by the combination of dissolution and argilla- 


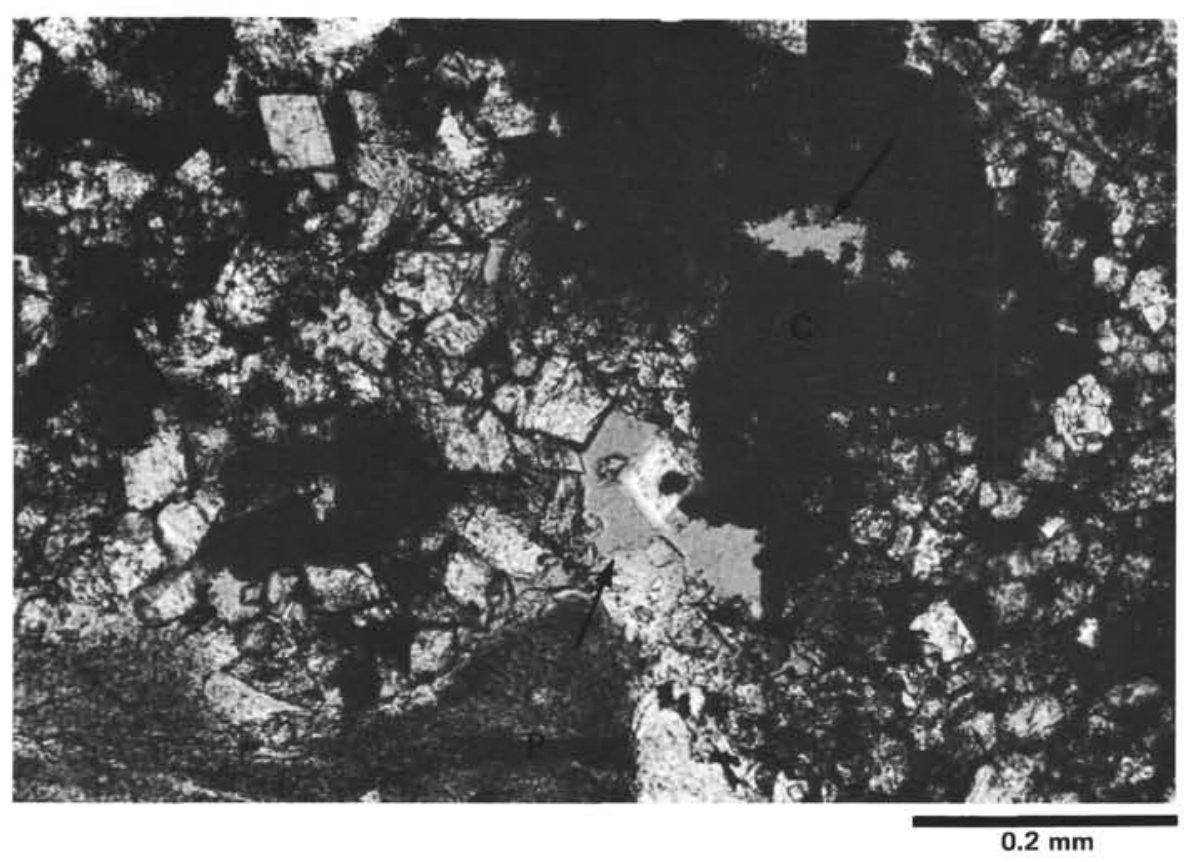

Figure 3. Texture near the contact of a sandstone lense in dolomitized limestone. Dolomite forms generally clear euhedral to subhedral rhombs. $\mathrm{P}=$ vacuolized plagioclase; $\mathrm{C}=$ patch of micrite with a clotted texture. The latter may be a micritized terrigenous clast. Arrows indicate late-stage dissolution pores. Sample 537-11-1, $99 \mathrm{~cm}$.

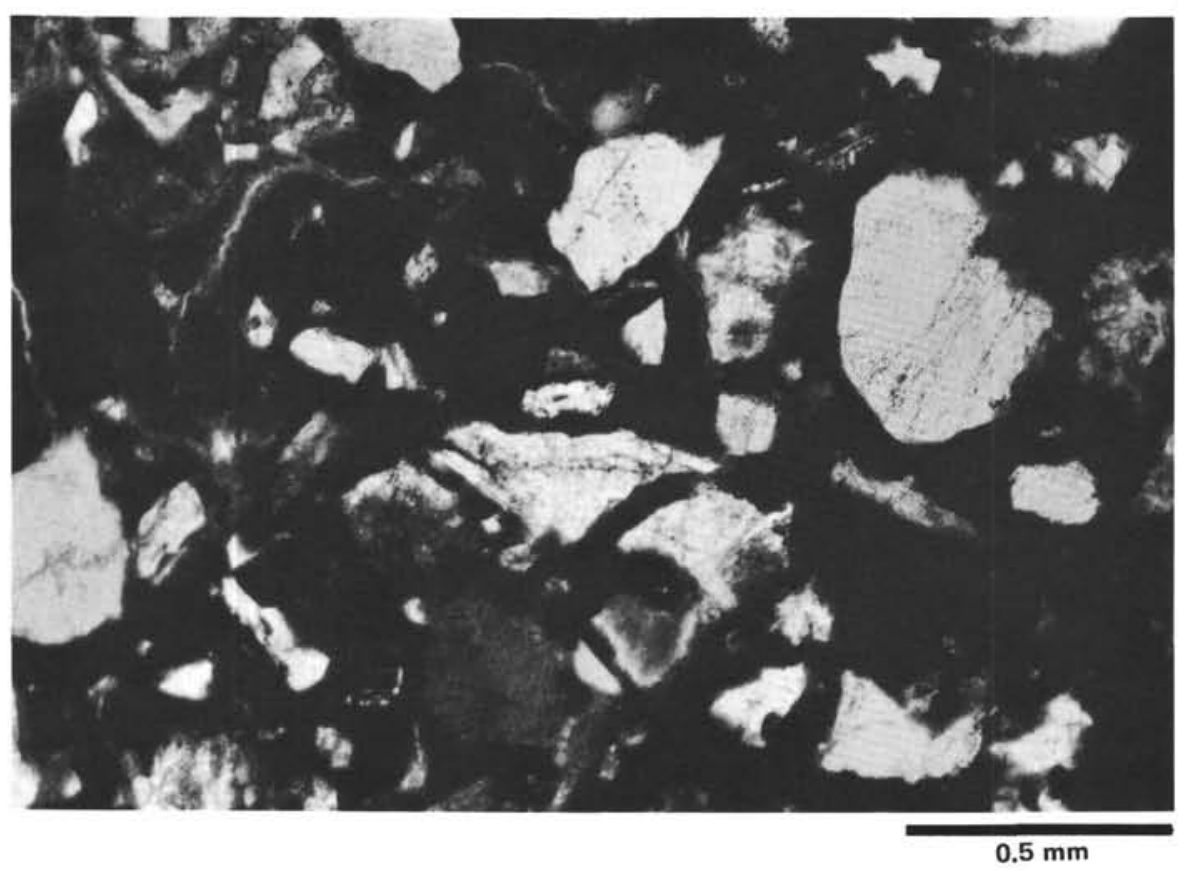

Figure 4. Part of a red sandstone bed where the hematite that pigments the matrix clays is still present. The amoeboid and unusual shapes of many detrital grains are the combined result of dissolution and partial replacement of grains in soils prior to deposition plus modifications during diagenesis. Sample 537-13-2, $17 \mathrm{~cm}$.

tion along fractures and cleavages (Fig. 8). Untwinned $\mathrm{K}$-feldspar greatly exceeds twinned (mostly grid-type) grains.

Plagioclase is nearly opaque from vacuolization and is not identifiable as to anorthite content by optical methods. Albite twins are common. Grains show no signs of rounding by abrasion.
The nonframework part of the sandstone samples is mixed-layer clay with $50 \%$ expandable layers as determined by X-ray diffraction (XRD). Hematite stains the clays so strongly in many places that it obscures textural details (Figs. 4 and 8 ). The hematite has a patchy distribution (Fig. 8) and is absent from the margins of long, linear pores (Fig. 6) that probably represent unfilled pri- 


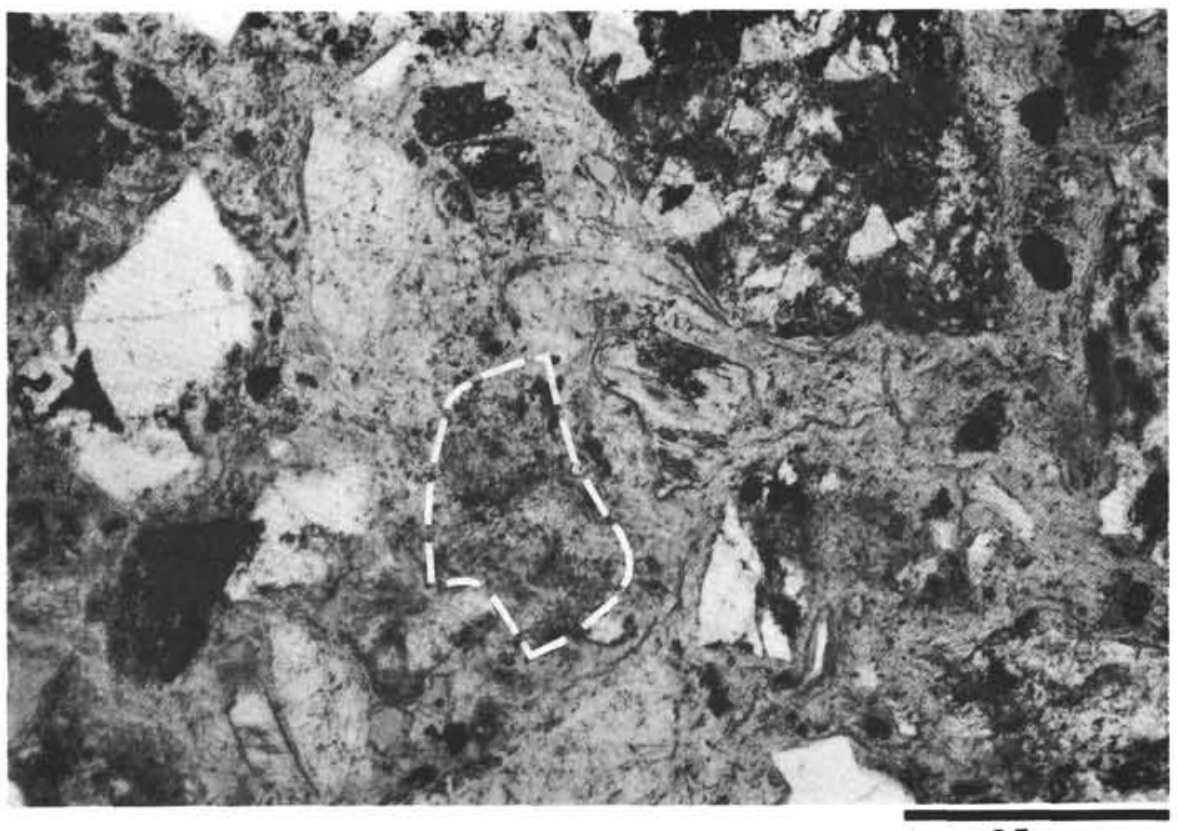

$0.5 \mathrm{~mm}$

Figure 5. Arkose with extensive clay matrix and a loosely packed sand framework. Loose packing is typical of sandstones in which the clay has an early diagenetic origin by infiltration, by precipitation in pores, and by replacement of unstable grains. $\mathrm{G}=$ graphic granite. The dashed line outlines a clay pseudomorph of a detrital grain. Sample 537-13-1, $5 \mathrm{~cm}$.

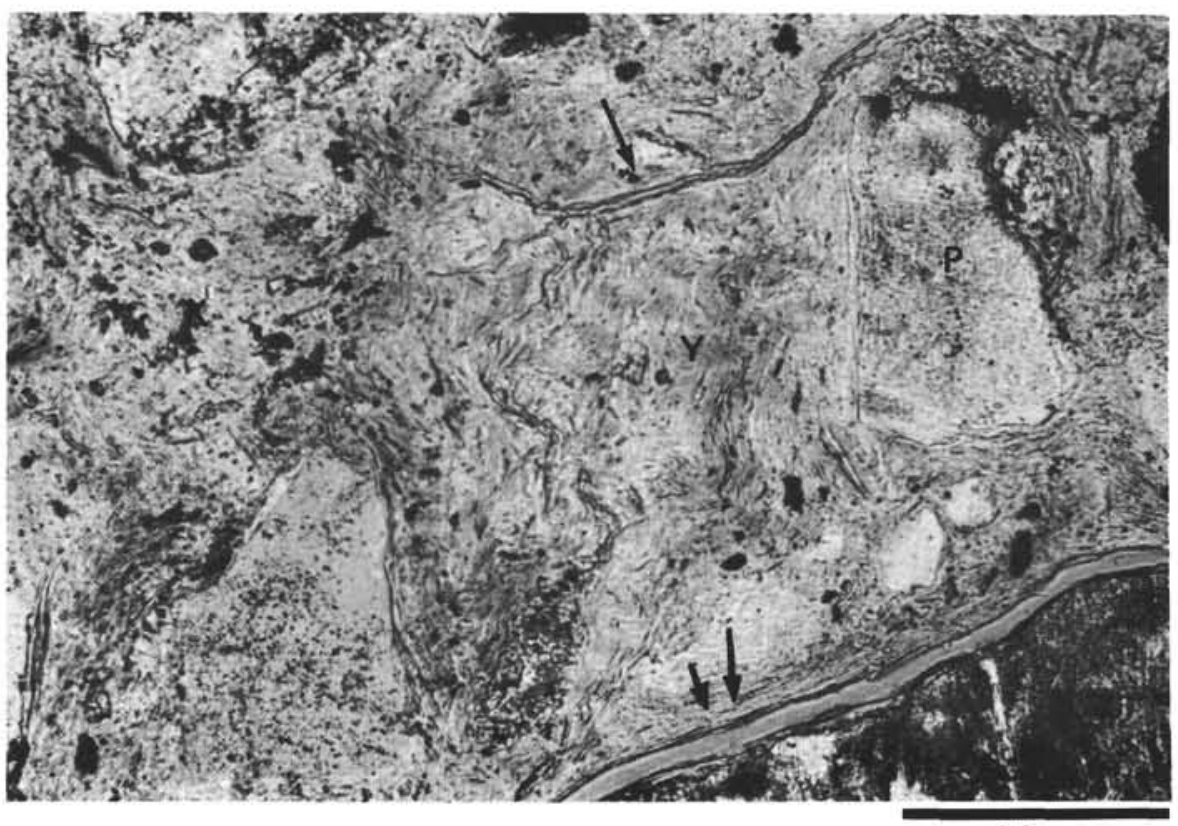

$0.2 \mathrm{~mm}$

Figure 6. Textural variation of clay matrix: finer-grained clay with mosaic texture at $\mathrm{X}$; coarsergrained clay that may be pseudo-morphous after feldspar at $\mathrm{Y}$. The single arrow identifies a long, linear pore that may be a primary pore; the double arrow indicates an artifact of sample preparation. $\mathrm{P}=$ plagioclase. Sample $537-13-1,5 \mathrm{~cm}$.

mary pores. The absence of hematite along these linear pores is most likely the result of its local removal by reaction with $\mathrm{H}_{2} \mathrm{~S}$-bearing formation waters that passed through the rocks, but it may reflect the accumulation of clays after the precipitation of hematite stopped. It is uncertain which of the long, linear pores visible in thin section developed upon desiccation during sample preparation and which existed in situ.

The clay matrix has several textures. Most clay occurs as an interlocking, microcrystalline mosaic whose indi- 


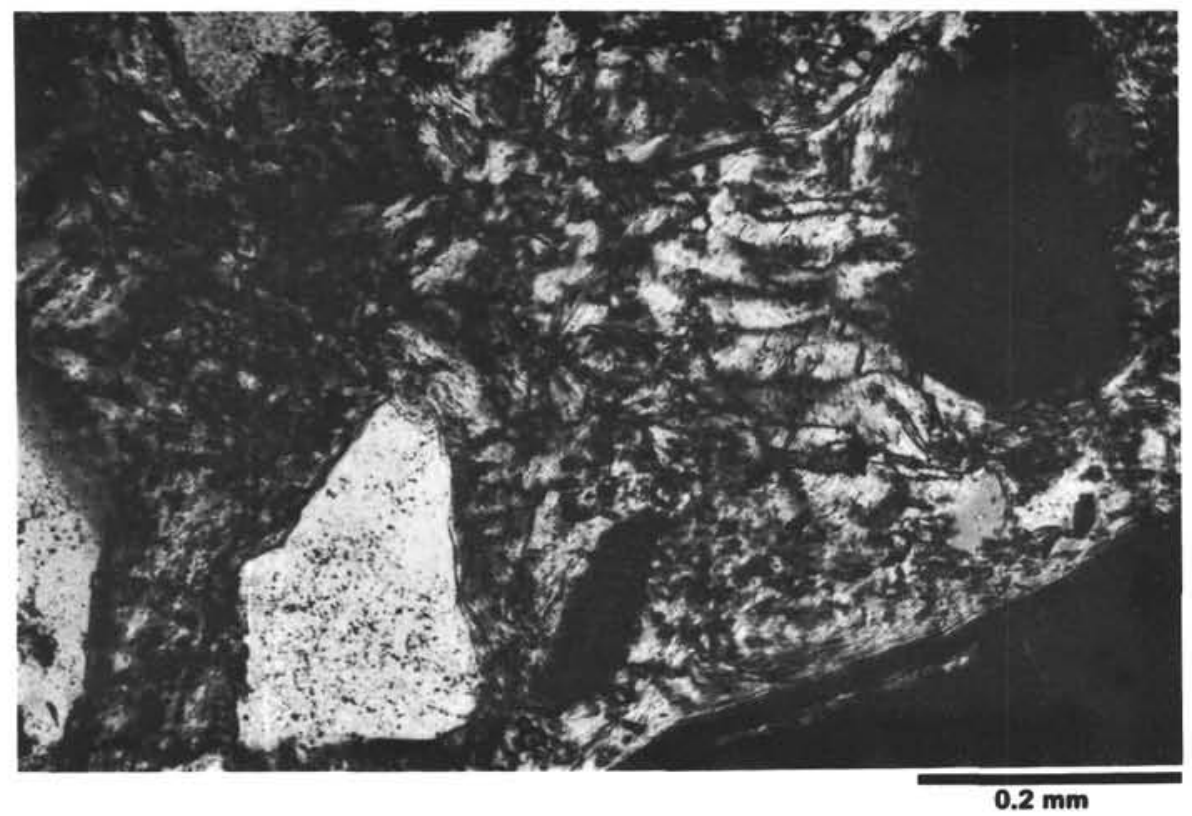

Figure 7. Same as Figure 6; crossed polars. The undulosity shown by the clay at $Y$ (above) is the result of compactional deformation of the clay.

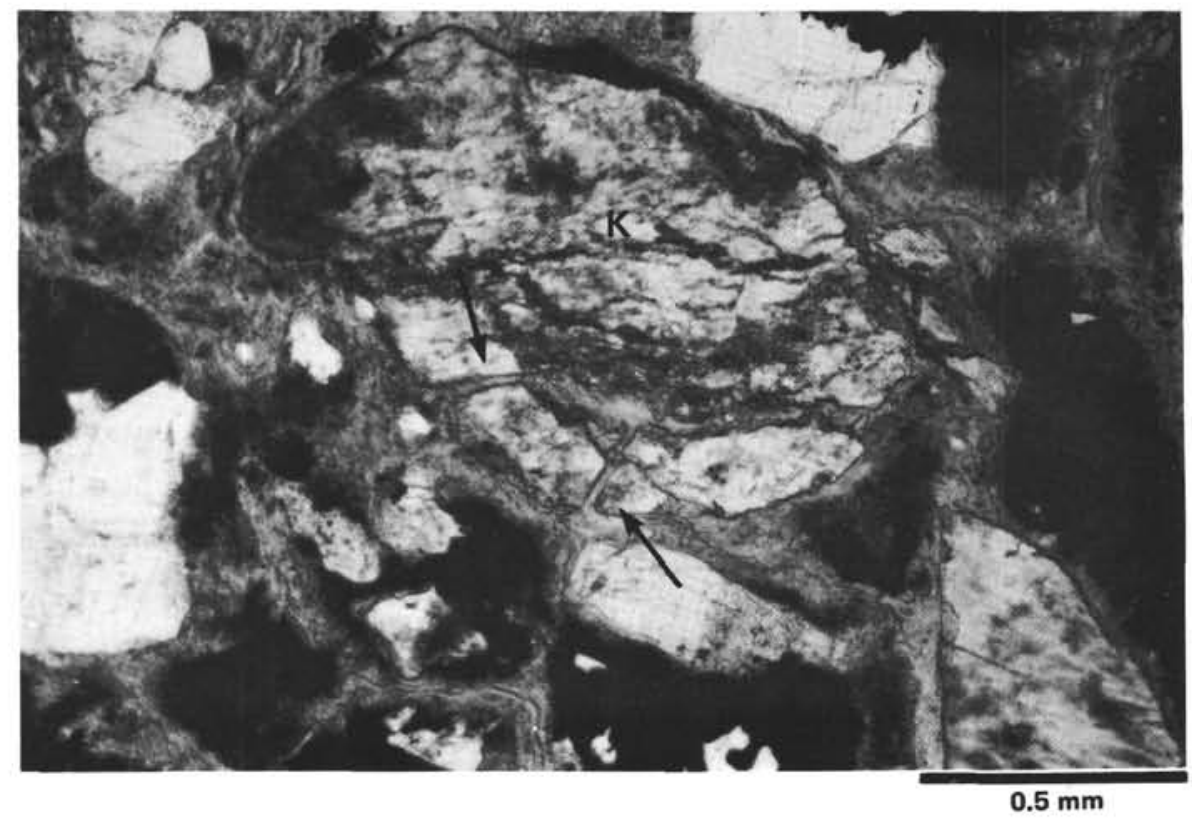

Figure 8. This sample shows a patchy distribution of hematite-pigmented clay (opaque) and hematite-free clay plus a $\mathrm{K}$-feldspar grain $(\mathrm{K})$ that has been dismembered through dissolution along cleavages and fractures (arrows). Sample 537-13-1, $112 \mathrm{~cm}$.

vidual grain clusters in thin section are 10 to $20 \mu \mathrm{m}$ wide, but in places there are fibrous bundles with sheaves $40 \mu \mathrm{m}$ in diameter. There are several large, fibrous aggregates up to $300 \mu \mathrm{m}$ long that are probable pseudomorphs of feldspar (Figs. 6 and 7). The clays adjacent to detrital sand grains are parallel with detrital grain margins (Figs. 6 and 7), having a texture that is typical of clay skins that form where clay filters into the sand from descending ground water (cf. Crone, 1974).

\section{DIAGENETIC HISTORY}

The diagenetic events recognizable in sandstones of Unit III (Core 537-11) and their inferred sequence from first to last are:

1) formation of K-feldspar overgrowths on detrital K-feldspar;

2) replacement of much feldspar, chiefly plagioclase, by micrite; 


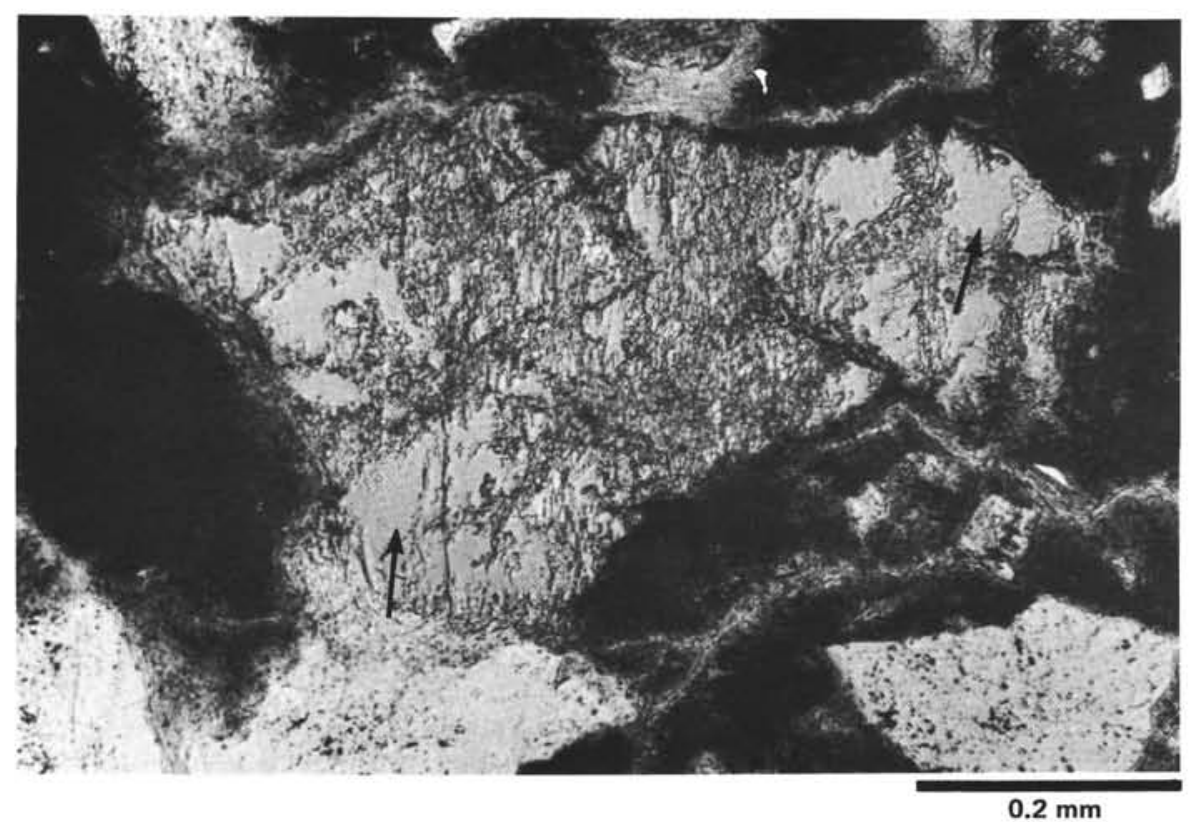

Figure 9. Skeletal remnant of a K-feldspar grain that has been dissolved in situ. The clear areas indicated by arrows show the pores. Very dark areas are hematite-pigmented clay matrix. Sample $537-13-2,7 \mathrm{~cm}$.

3) dolomitization of much micrite;

4) development of secondary porosity $(\sim 10 \%)$ by dissolution of feldspar and micrite; and

5) generation of pyrite possibly by the reaction of migrating $\mathrm{H}_{2} \mathrm{~S}$ with hematite that was originally present as grain coatings (now gone) on detrital grains.

The diagenetic events recognizable in sandstones of Unit IV (Core 537-13) and their inferred sequence from first to last are:

1) Clay skins developed on detrital sand grains during the infiltration of meteoric water.

2) An extensive reaction occurred between meteoric pore water and unstable detrital grains (chiefly plagioclase and ferromagnesian minerals) and the subsequent precipitation of mixed-layer clays in the primary and secondary pores of the sand. Plagioclase and some K-feldspar grains were intensely vacuolized.

3) Simultaneous with Step 2 was the precipitation of hematite or a precursor iron hydroxide with the clays to produce the red color of the rocks. The iron-oxide is a by-product of oxidation of ferromagnesian minerals.

4) There was minor development of secondary pores by late-stage dissolution of $\mathrm{K}$-feldspar.

5) Migration of $\mathrm{H}_{2} \mathrm{~S}$ through the sandstone locally reduced the hematite and bleached the rocks.

\section{COMPARISON OF DIAGENETIC EVENTS}

Although the sandstones in the two different core sections probably had the same original composition-essentially granite wash-they were deposited in different environments and underwent totally different diagenetic histories, producing sandstones that are remarkably different in the two cores.

Arkose that was deposited as inferred fluvial (alluvial fans?) deposits in the deeper core section underwent severe diagenetic alteration that is typical of one route of diagenesis that leads to the formation of red beds (Walker et al., 1978). Vadose and phreatic meteoric water reacted with unstable detrital minerals to produce large amounts of clays that were precipitated in pores that were pigmented by minor amounts of hematite formed by oxidation of iron in ferromagnesian minerals. All ferromagnesian minerals and most plagioclase grains were lost by dissolution and hydrolysis.

In the younger unit sands were deposited in a marine environment, possibly as fan delta deposits, and are interbedded with carbonate mud. Although these sands did not become red, unstable minerals were also lost in these samples and were replaced by calcite. The saline pore fluids precipitated small amounts of K-feldspar overgrowths. Secondary porosity of significant amounts formed during dolomitization of the micrite component of the rock and also during a late-stage diagenetic event.

Porosity is present in sandstone from both stratigraphic units and is of sufficient abundance in younger beds to form a respectable hydrocarbon reservoir rock. Pores in the red beds include late-formed secondary pores that formed by the dissolution of feldspar (these pores are free of clays) and primary pores among clay cement minerals. In Unit III all pores are secondary; these include those formed by the dissolution of feldspar and micrite. The time of dolomitization is unknown.

\section{REFERENCES}

Crone, A. J., 1974. Experimental studies of mechanically infiltered clay matrix in sand. Geol. Soc. Am. Abstract with Programs, 6:701. (Abstract)

Walker, T. R., Waugh, B., and Crone, A. J., 1978. Diagenesis in firstcycle alluvium of Cenozoic age, southwestern United States and northwestern Mexico. Geol. Soc. Am. Bull., 89:19-32.

Date of Initial Receipt: August 16, 1982

Date of Acceptance: February 4, 1983 